\title{
What can countries learn from Hong Kong's response to the COVID-19 pandemic?
}

\author{
Samuel Y.S. Wong MD MPH, Kin On Kwok PhD, Francis K.L. Chan MD
}

- Cite as: CMAJ 2020 May 11;192:E511-5. doi: 10.1503/cmaj.200563; early-released April 24, 2020

H

ong Kong, a special administrative region of the People's Republic of China, is located in southern China and shares a border with mainland China. It has a population of more than 7.45 million and is a regional travel hub, with the eighth busiest airport in the world and with more than 70 million travellers passing through it each year. The population density in Hong Kong is one of the highest in the world with 17311 people per square mile (6659 people per square kilometer). This, together with its proximity to the mainland, makes Hong Kong vulnerable to being severely affected by the coronavirus disease 2019 (COVID-19) pandemic.

The first case of COVID-19 in Hong Kong was reported on Jan. 22, 2020. From January to March 2020, 96709 tests were performed, and by Apr. 14, 2020, 1010 people had tested positive for severe acute respiratory syndrome coronavirus 2 (SARS-CoV-2) and 4 had died from COVID-19. ${ }^{1}$ Given its unique circumstances, Hong Kong has done relatively well in controlling the spread of COVID-19 (Figure 1; Appendix 1, available at www.cmaj.ca/ lookup/suppl/doi:10.1503/cmaj.200563/-/DC1). We analyze the potential reasons for Hong Kong's early success in preparing for and reacting to the SARS-CoV-2 threat, so that other countries may be able to learn from Hong Kong's experience.

\section{What did Hong Kong do to control COVID-19?}

Hong Kong's government implemented multiple measures even before the first case of COVID-19 was diagnosed. Hong Kong's multipronged approach is summarized in Box 1; it included border controls, social distancing, quarantine, aggressive contact tracing, testing, screening and surveillance.

\section{Border control and social distancing}

Before the first locally reported case, Hong Kong expected and was on the alert for cases of COVID-19. On Jan. 3, 2020, noncontact temperature screening (using thermal imaging) was implemented at border checkpoints for travellers arriving from Wuhan, China, by rail or air transportation. ${ }^{2}$ Subsequently, visitors from Wuhan and other affected areas of China were not allowed to enter Hong Kong. Eleven of the city's 14 border crossings were closed with the aim to maintain only essential traffic, and traveller screening interventions included body

\section{KEY POINTS}

- Hong Kong has a relatively low number of cases of coronavirus disease 2019 (COVID-19) despite being an international travel hub and despite its proximity to Wuhan, China.

- Public health measures, including border control and social distancing, high-volume testing for severe acute respiratory syndrome coronavirus 2 (SARS-CoV-2), aggressive contact tracing and quarantine centres, likely contributed substantially to the control, especially during the early period after the first confirmed case.

- The practice of personal protective behaviours, including use of face masks, by most people in Hong Kong may also have played an important role in controlling the spread of SARS-CoV- 2 in the region.

temperature checks and questions about symptoms of COVID19 at airports and all borders. Primary and secondary schools under the Education Bureau were closed on Jan. 27, followed soon afterward by colleges and universities. Working from home was implemented for civil servants (first from Jan. 29 to Mar. 1, then suspended, and restarted on Mar. 23 until the time of writing this analysis). Owing to a growing number of cases in people returned from overseas, the Hong Kong government banned the entry of all non-Hong Kong residents from overseas countries (except those from Taiwan and Macao), on Mar. 25, $2020 .^{3}$ On Mar. 29, gatherings of more than 4 people in public places were prohibited, ${ }^{4}$ and on Apr. 1 , karaoke, mah-jong parlours and nightclubs were forced to close. ${ }^{5}$

\section{Contact tracing, testing and mandatory quarantine}

A 14-day quarantine period for everyone entering Hong Kong from the mainland was mandated and enforced on Mar. 19, $2020 .{ }^{6}$ Aggressive contact tracing and quarantine of close contacts of confirmed cases was undertaken, with several quarantine centres converted from existing retreat centres, a camping site and a new housing estate. People with close contact to infected people but without symptoms were not tested for COVID-19. However, these contacts, as well as travellers arriving in or returning to Hong Kong in the past 14 days before Mar. 25 from regions with a high number of COVID-19 cases (including 


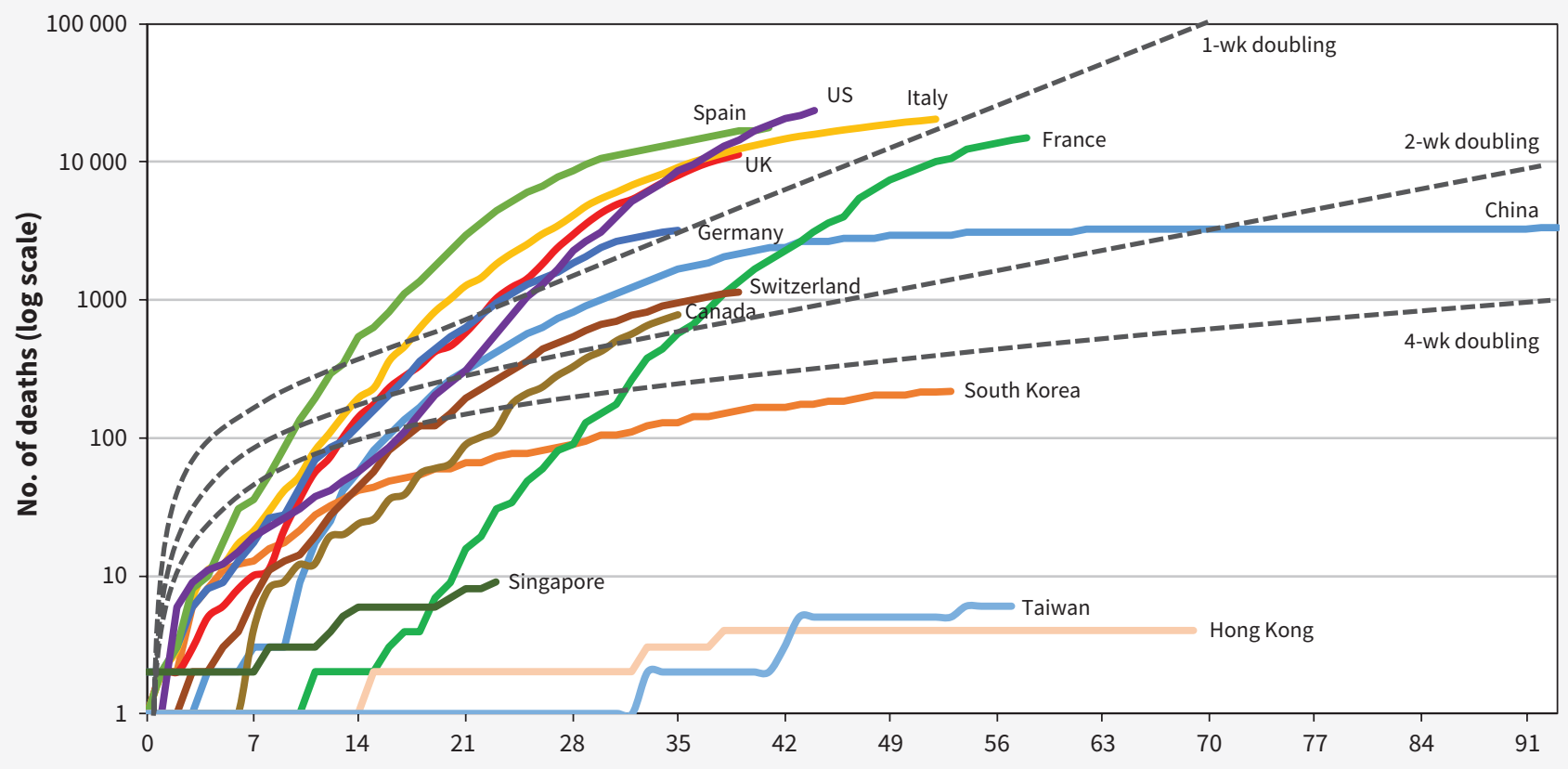

Time since first death, $d$

Figure 1: Cumulative number of deaths from coronavirus disease 2019 (COVID-19) (data as of Apr. 13, 2020). Note: Basic unit for reference lines of doubling is 200 deaths.

\section{Box 1: Public health measures implemented during the COVID-19 pandemic by the Hong Kong government}

Border control and social distancing

Contact tracing, quarantine and testing

Screening and surveillance

Communication with public
- Temperature screening at border checkpoints

- Health declaration at border checkpoints

- Banning of high-risk travellers (e.g., travellers from Hubei, then all non-Hong Kong residents, closure of borders)

- School closure

- Working from home arrangements

- Closure of leisure facilities and cancellation of recreational, sports and cultural programs

- Prohibition of gatherings of more than 4 people in public places

- Closure of karaoke, mah-jong parlours and nightclubs (implemented after the second wave of the epidemic in March)

- Designated quarantine centres to accommodate close contacts of confirmed cases and people with high risk who enter Hong Kong

- Mandatory self-quarantine for some of the close contacts of confirmed cases, with monitoring of compliance by electronic wristbands

- Testing of returning travellers at the airport and at their own residence; treatment or hospital admission arranged by the Centre for Health Protection (www.chp.gov.hk/en) if results are positive

- Travellers arriving at the airport from countries with a large number of infected cases undergo deep throat saliva tests for SARS-CoV-2

- Enhanced laboratory surveillance program for patients attending public primary care clinics and accident and emergency departments with fever and mild respiratory symptoms

- Enhanced laboratory surveillance with testing at private clinics

- List of buildings, flights, trains and ships relevant to the confirmed cases, countries and areas with reported cases as well as health advice and a hotline for suspected cases provided on the website of the Centre for Health Protection

- Daily press conferences

- Advice to public to protect themselves and others, including keeping their hands clean, wearing masks as appropriate and maintaining coughing etiquette; members of the public urged to go out less, avoid social activities and maintain proper social distancing 
Daegu and Gyeongsangbuk-do in Korea; Iran; and EmiliaRomagna, Lombardy and Veneto in Italy) were sent to quarantine centres. These centres are not health care facilities but are places for accommodation with monitoring and provision of meals by staff hired by Hong Kong's Department of Health.

After Mar. 25, all returning Hong Kong residents were asked to complete a mandatory 14-day self-quarantine under surveillance using electronic wristbands paired with a mobile app. Anyone found to have not complied with self-quarantine was considered to have committed a criminal offence. Up to Mar. 30, 54 people were found guilty of breaching quarantine orders and were sent to quarantine centres, ${ }^{7}$ and 3 people were found guilty by law and were imprisoned for 10 days to 3 months. ${ }^{8}$

\section{Screening and surveillance}

An enhanced laboratory surveillance program for patients attending public primary care clinics and accident and emergency departments with fever and mild respiratory symptoms (Jan. 13 and ongoing) ${ }^{9}$ was implemented to provide timely feedback on the severity of the outbreak in the community. The program contributed data for policy-makers to decide on whether designated primary care clinics needed to be opened for people with fever or relevant symptoms. To facilitate accurate identification of COVID-19 among suspected cases in clinical settings, the government linked the record system of the Immigration Department with that of the public hospitals to provide an accurate travel history for case identification.

For screening, diagnostic tests were administered at the airport for Hong Kong residents returning from countries with a high prevalence of COVID-19, such as the United States, United Kingdom, Italy and other European countries. During the second wave of the COVID-19 epidemic in Hong Kong, with almost all newly reported cases being returning travellers who were infected outside of Hong Kong, a deep throat saliva test for SARS-CoV-2 ${ }^{10}$ at a designated area in the airport was required for all inbound travellers who had been in the US, the UK, European countries and Hubei province (regardless of symptoms), those aged 65 years and older, and those residing with adults aged 65 and older. People who tested positive were admitted to hospital for treatment, and their close contacts (those who travelled with them) were sent to the quarantine centres. People who tested negative could choose compulsory quarantine either at home or at a designated place (e.g., hotel) for 14 days.

These measures appear to have been effective in curbing the potential exponential rise of cases during the early period of the epidemic, ${ }^{11}$ and implementation of more recent measures appear to have slowed the increase of local cases (Figure 2).

\section{Communication with the general public}

The website of Hong Kong's Centre for Health Protection (www. chp.gov.hk/en) provides a list of buildings and information on the flights, trains or ships with passengers with COVID-19. If a flight is found to have carried a person who tested positive for COVID-19, the flight number is placed on the website. The neighbouring passengers of the infected person would be contacted, regarded as close contacts and sent to the quarantine centre. For the rest of the passengers, the information on the website is provided to ensure transparency and for other passengers to self-monitor for symptoms (no further action is taken by the government with regard to passengers who were not close neighbours of the index passenger). The information provided on the list of buildings with infected people serves a similar purpose as part of a communication strategy to increase transparency of information.

Updates on the latest number of COVID-19 cases of all affected countries as well as a geographical map of Hong Kong highlighting areas with confirmed cases are available on the same website. Health advice and the number of a hotline regarding people who are suspected to have COVID-19 are provided, and a daily press conference reporting on the latest local situation on COVID-19 has been held by government and hospital officials since January.

\section{What have people in Hong Kong done to reduce their infection risk?}

Likely owing to their experience with SARS in 2002-2003, which resulted in 1755 people infected and 299 deaths in Hong Kong, ${ }^{12}$ the region's residents have adopted a high level of personal infection-control measures. A survey of the general population conducted hours after the first COVID-19 case was confirmed showed that more than $95 \%$ of respondents reported washing their hands frequently and $99 \%$ wore face masks. ${ }^{13}$ In fact, use of face masks has become a cultural norm in Hong Kong during the current pandemic.

Although all would agree that handwashing is important for infection control, the wearing of face masks by asymptomatic people is controversial. The World Health Organization does not currently recommend that asymptomatic individuals who are not in close contact with infected people wear a surgical face mask in public. ${ }^{14}$ This contrasts sharply with practices adopted by people in East Asian cities such as Hong Kong, Taiwan and Singapore, where most people have chosen to use surgical face masks in public places. ${ }^{15}$

There is currently no good evidence for the effects of using face masks in public to reduce the risk of respiratory illnesses, although lack of good evidence does not rule out benefit. It is difficult to conduct randomized controlled trials on this topic. ${ }^{16} \mathrm{~A}$ 2015 meta-analysis ${ }^{17}$ suggested that early use of face masks by healthy individuals may prevent them from contracting influenza-like illness from infected household members. In addition, case-control studies conducted during the outbreak of SARS in both Hong Kong ${ }^{18}$ and Beijing ${ }^{19}$ suggested that the frequent use of face masks (mainly surgical masks) by the general population in public places may have had a protective role against contracting SARS compared with infrequent use of face masks, after accounting for potential confounders such as age, sex, chronic illnesses, visits to a health care facility and eating out. With the extra protective practices of the general population during the SARS epidemic in Hong Kong, the incidence of respiratory viral infections was substantially reduced. ${ }^{20}$ 


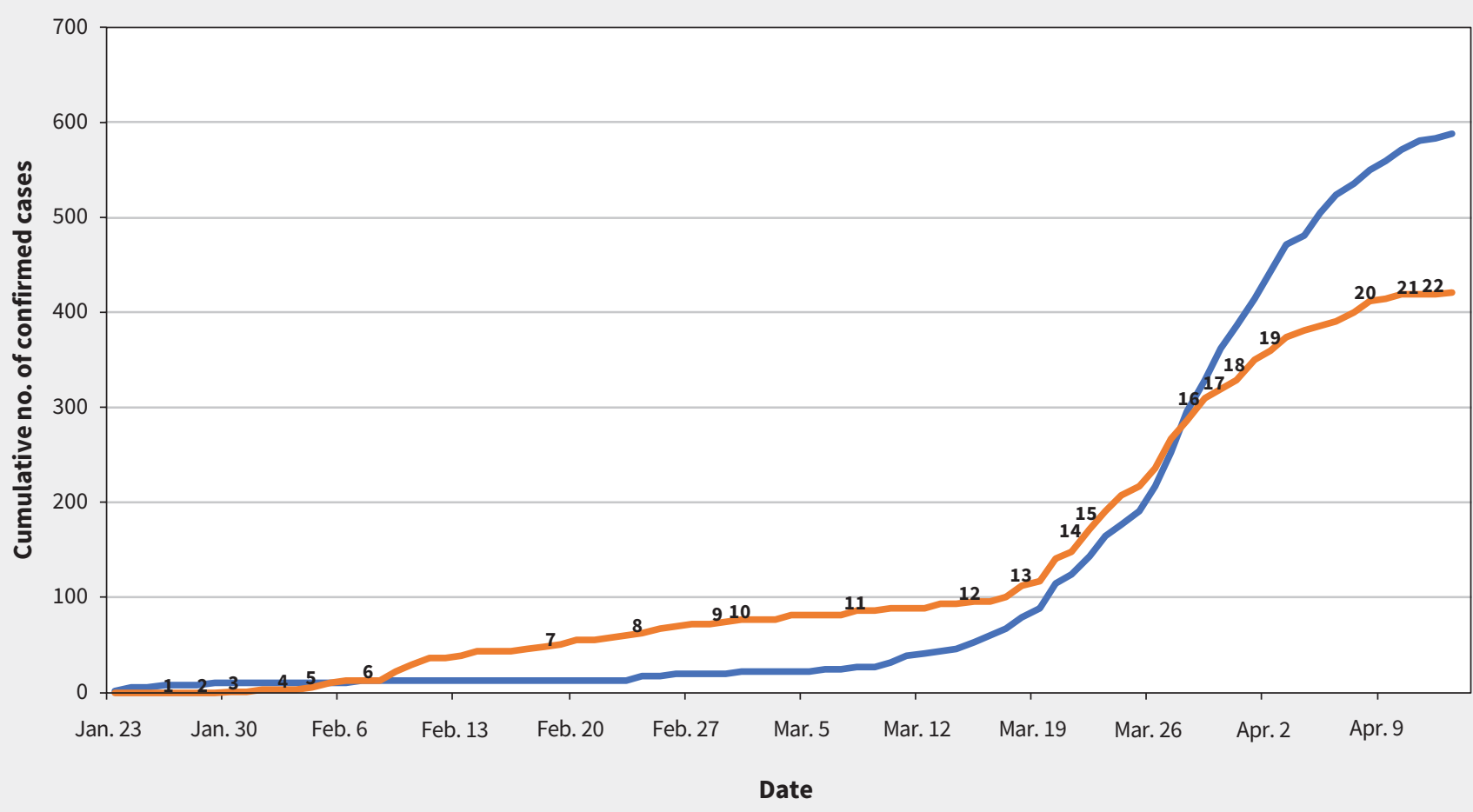

\begin{tabular}{|c|c|}
\hline No. of confirmed imported cases (cumulative) & No. of confirmed local cases (cumulative) \\
\hline \multicolumn{2}{|l|}{ Public health measures } \\
\hline 1. Jan. 26: Hubei travellers banned & 15. Mar. 23: Reimplementation of work from home for civil servants \\
\hline 2. Jan. 29: Leisure facilities closed, civil servants work from home & 16. Mar. 29: Groups of $>4$ prohibited in public \\
\hline 3. Jan. 31: School closure & 17. Mar. 30: 400 additional isolation beds in hospitals \\
\hline 4. Feb. 3: Closure of almost all borders to mainland & 18. Apr. 1: Karoke, nightclubs closed \\
\hline 5. Feb. 4: CHP report locations of suspected cases online & 19. Apr. 3: Enhanced laboratory surveillance program provides free COVID-19 testing \\
\hline 6. Feb. 8: Home quarantine for mainland travellers & service for inbound travellers; bars and premises selling liquor closed for $14 \mathrm{~d}$ \\
\hline \multirow{3}{*}{$\begin{array}{l}\text { 7. Feb. 19: Enhanced laboratory surveillance program for GOPCS and AEDs } \\
\text { 8. Feb. 25: Residents returning from South Korea regions to stay in quarantine centre } \\
\text { 9. Mar. 1: Home quarantine for travellers from Iran and Italy }\end{array}$} & 20. Apr. 8: All asymptomatic inbound travellers at the airport required to have \\
\hline & deep throat saliva samples taken at the temporary specimen collection centre \\
\hline & for COVID-19 testing \\
\hline \multirow{2}{*}{$\begin{array}{l}\text { 10. Mar. 2: Civil servants resume work } \\
\text { 11. Mar. 9: Enhanced laboratory surveillance program for private clinics }\end{array}$} & 21. Apr. 10: Restaurants to serve half their capacity of customers, separating each table \\
\hline & by at least $1.5 \mathrm{~m}$ and allowing only 4 people to be seated at a table until Apr. 23 \\
\hline \multirow{3}{*}{$\begin{array}{l}\text { 12. Mar. 17: Home quarantine for travellers from South Korea } \\
\text { 13. Mar. 19: Home quarantine for all inbound travellers; electronic wristbands activated } \\
\text { 14. Mar. 22: Enhanced testing for returning travellers }\end{array}$} & 22. Apr. 11: Confinees at quarantine centres to be quarantined for first $10 \mathrm{~d}$, then put \\
\hline & under home quarantine for the remaining $4 \mathrm{~d}$ and to wear electronic wristbands \\
\hline & \\
\hline
\end{tabular}

Figure 2: Number of confirmed imported and local cases of coronavirus disease 2019 (COVID-19) in Hong Kong (Jan. 23, 2020, to Apr. 13, 2020) according to the Centre for Health Protection (CHP), Hong Kong. Note: AED = accident and emergency department, GOPC = general outpatient clinic.

Transmission of SARS CoV-2 from asymptomatic infected individuals has been reported, ${ }^{21}$ and the viral load can be high during the early phase of infection. ${ }^{22}$ An argument for the potential benefits of use of face masks by the general population in public places is that masks may provide some limited protection against transmission from asymptomatic carriers to healthy individuals. ${ }^{23}$

Concerns have been expressed that members of the public wearing surgical face masks will create a shortage for those who need them the most, such as health care workers, ${ }^{24}$ and that the use of face masks may either give people a false sense of confidence ${ }^{14}$ or, if masks are worn inappropriately, may inadvertently increase people's risk of infection. ${ }^{25}$ However, results from our survey suggest that use of a face mask is not associated with a lower rate of handwashing. ${ }^{13}$ Moreover, people can be taught how to wear face masks properly. Some public health leaders have recently changed their messaging on face masks, and some experts have called for adoption of the precautionary principle and called for universal use of face masks, with some emerging evidence to support its effectiveness. ${ }^{11,23}$

\section{Conclusion}

Hong Kong's experience of the 2003 SARS epidemic may explain both the government and residents' enhanced public health 
preparedness and willingness to respond quickly in the face of the COVID-19 threat. Other countries may learn from Hong Kong's aggressive containment approach, including tracing all close contacts followed by mandatory, supported quarantine of these contacts. However, as all public health interventions have potential benefits and risks, a balanced analysis that takes local contextual factors into account is needed so that the most appropriate actions are taken.

\section{References}

1. Latest situation of coronavirus disease (COVID-19) in Hong Kong. Hong Kong (China): Centre for Health Protection, Department of Health, The Government of the Hong Kong Special Administrative Region. Available: http://chp-dashboard. geodata.gov.hk/covid-19/en.html (accessed 2020 Apr. 14).

2. CE tours XRL health checkpoint. News.gov.hk 2020 Jan. 3. Available: www.news. gov.hk/eng/2020/01/20200103/20200103_193732_648.html?type=category\& name=wuhan\&tl=t (accessed 2020 Mar. 18).

3. HK to ban non-resident arrivals. News.gov.hk 2020 Mar. 23. Available: www. news.gov.hk/eng/2020/03/20200323/20200323_164827_699.html (accessed 2020 Apr. 2).

4. Group gathering ban gazetted. News.gov.hk 2020 Mar. 28. Available: www. news.gov.hk/eng/2020/03/20200328/20200328_110413_745.html (accessed 2020 Apr. 2).

5. Karaokes, clubs, mahjong parlours ordered to close. Rthk.hk 2020 Apr. 1. Available: https://news.rthk.hk/rthk/en/component/k2/1518212-20200401.htm? spTabChangeable $=0$ (accessed 2020 Apr. 2).

6. Government to impose mandatory quarantine on people entering Hong Kong from Mainland [press release]. Hong Kong (China): The Government of Hong Kong Special Administrative Region; 2020 Feb. 5. Available: www.info.gov.hk/ gia/general/202002/05/P2020020500793.htm (accessed 2020 Mar. 18).

7. 54 netted for quarantine breaches. News.gov.hk 2020 Mar. 26. Available: www. news.gov.hk/eng/2020/03/20200326/20200326_221347_495.html (accessed 2020 Apr. 2).

8. 3 jailed for violating quarantine. News.gov.hk 2020 Mar. 30. Available: www. news.gov.hk/eng/2020/03/20200330/20200330_174317_389.html (accessed 2020 Apr. 2).

9. DH sets up temporary specimen collection centre to speed up specimen collection from inbound travellers from overseas [press release]. Hong Kong (China): The Government of Hong Kong Special Administrative Region; 2020 Mar. 25. Available: www.info.gov.hk/gia/general/202003/25/P2020032500820. htm (accessed 2020 Apr. 2).

10. DH strengthens health quarantine and testing arrangements for inbound travellers [press release]. Hong Kong (China): The Government of Hong Kong Special Administrative Region; 2020 Apr. 7. Available: www.info.gov.hk/gia/ general/202004/07/P2020040700753.htm (accessed 2020 Apr. 14).

11. Cowling BJ, Ali ST, Ng TW, et al. Impact assessment of non-pharmaceutical interventions against COVID-19 and influenza in Hong Kong: an observational study. medRxiv 2020 Mar. 16. doi: 10.1101/2020.03.12.20034660.

12. Naylor CD, Chantler C, Griffiths S. Learning from SARS in Hong Kong and Toronto. JAMA 2004;291:2483-7.
13. Kwok KO, Li KK, Chan HH, et al. Community responses during the early phase of the COVID-19 epidemic in Hong Kong: risk perception, information exposure and preventive measures. medRxiv 2020 Feb. 27. doi: 10.1101/2020.02.26.20028217.

14. Advice on the use of masks in the community, during home care and in healthcare settings in the context of the novel coronavirus (2019-nCoV)outbreak: interim guidance, 29 January 20202. Geneva: World, Health Organization; 2020. Available: https://apps.who.int/iris/handle/10665/330987 (accessed 2020 Apr. 2).

15. Leung CC, Lam TH, Cheng KK. Mass masking in the COVID-19 epidemic: people need guidance. Lancet 2020;395:945.

16. Chan KH, Yuen KY. COVID-19 epidemic: disentangling the re-emerging controversy about medical facemasks from an epidemiological perspective. Int J Epidemio/ 2020 Mar. 31 [Epub ahead of print]. dyaa044. doi: 10.1093/ije/dyaa044.

17. Maclntyre CR, Chughtai AA. Facemasks for the prevention of infection in health care and community settings. BMJ 2015;350:h694.

18. Lau JT, Tsui H, Lau M, et al. SARS transmission, risk factors and prevention in Hong Kong. Emerg Infect Dis 2004;10:587-92.

19. Wu J, Xu F, Zhou W, et al. Risk factors for SARS among persons without known contact with SARS patients, Beijing, China. Emerg Infect Dis 2004;10:210-6.

20. Lo JY, Tsang TH, Leung YH, et al. Respiratory infections during the SARS outbreak, Hong Kong, 2003. Emerg Infect Dis 2005;11:1738-41.

21. Bai Y, Yao L, Wei T, et al. Presumed asymptomatic carrier transmission of COVID-19. JAMA 2020 Feb. 21 [Epub ahead of print]. doi: 10.1001/jama.2020.2565.

22. Zou L, Ruan F, Huang M, et al. SARS-CoV-2 viral load in upper respiratory specimens of infected patients. N Engl J Med 2020;382:1177-9.

23. Greenhalgh T, Schmid MB, Czypionka T, et al. Face masks for the public during the covid-19 crisis. BMJ 2020;369:m1435.

24. Ranney ML, Griffeth V, Jha AK. Critical supply shortages - the need for ventilators and personal protective equipment during the COVID-19 pandemic. N Engl J Med 2020 Mar. 25 [Epub ahead of print].doi: 10.1056/NEJMp2006141.

25. Howard J. Masks may actually increase your coronavirus risk if worn improperly, surgeon general warns. CNN Health 2020 Mar. 2. Available: https://edition.cnn. com/2020/03/02/health/surgeon-general-coronavirus-masks-risk-trnd/index.html (accessed 2020 Apr. 2).

Competing interests: Francis Chan reports personal fees from Pfizer, AstraZeneca, Eisai, Takeda Pharmaceuticals, EA Pharma and the Japan Gastroenterological Endoscopy Society, and reports grants from Pfizer, AstraZeneca and Takeda (China) Holdings. No other competing interests were declared.

This article has not been peer reviewed.

Affiliations: The Jockey Club School of Public Health and Primary Care (Wong, Kwok) and Faculty of Medicine (Chan), Chinese University of Hong Kong, Hong Kong, China

Contributors: All of the authors contributed to the conception and design of the work. Samuel Wong drafted the manuscript. All authors revised the article, gave final approval of the version to be published and agreed to be accountable for all aspects of the work.

Correspondence to: Francis Chan, fklchan@cuhk.edu.hk 